\title{
ANALISIS TINGKAT PELAYANAN JALAN MENGGUNAKAN PERANGKAT LUNAK VISSIM PADA SIMPANG BERSINYAL CISALAK, KOTA DEPOK
}

\author{
Rakha Imaulanda $\mathrm{H}^{1}$, Dadang Suyadi ${ }^{2}$ \\ Email : rakhaimaulanda@gmail.com ${ }^{1}$, dsyd@unj.ac.id ${ }^{2}$ \\ Prodi D III Transportasi, Fakultas Teknik - Universitas Negeri Jakarta \\ Prodi D III Transportasi, Fakultas Teknik - Universitas Negeri Jakarta
}

\begin{abstract}
Abstrak. Simpang gerbang tol Cisalak I Kota Depok merupakan simpang yang menghubung antara Jalan. Ir. H. Juanda, Jalan Raya Bogor, Jalan Gas Alam, dan tentunya pintu masuk \& keluar tol Cisalak I. Dengan memiliki 6 lengan simpang, tentunya banyak konflik lalu lintas yang terjadi pada simpang gerbang tol Cisalak I, salah satunya ialah tundaan pada lengan simpang yang panjang sehingga kemacetan di setiap lengan simpang pada jam sibuk selalu terjadi dan ditambah dengan waktu siklus traffic light yang memakan cukup waktu yang lama sehingga terjadinya lama antrian. Tujuan penelitian ini untuk mengetahui lebih dalam kinerja lalu lintas tersebut. Metode yang digunakan ialah mengamati langsung ke lokasi penelitian dengan mengamati banyak volume kendaraan dengan berbagai macam jenis, arus fase kendaraan yang lewat pada simpang, dan waktu siklus traffic light, serta dengan menggunakan software Vissim sebagai permodelan dan mendapatkan hasil hitungan. Hasil dari penelitian didapatkan kapasitas pada Jalan Raya Bogor (arah Jakarta) sebesar 771,69 smp/jam, Jalan Ir. H. Juanda sebesar 542,92 smp/jam, Jalan Raya Bogor (arah Bogor) sebesar 612,21, dan Jalan Tol Cijago/Cisalak \& Gas Alam sebesasr 538,03 smp/jam dan Nilai derajat kejenuhan di tiap tiap simpang yaitu Jalan Raya Bogor (arah Jakarta) Sebesar 2,96, Jalan Ir. H. Juanda sebesar 3,52, Jalan Raya Bogor (arah Bogor) sebesar 2,77, dan Jalan Tol Cijago/Cisalak \& Gas Alam sebesasr 2,95, sehingga hasil level of service pada semua lengan simpang $\mathrm{F}$ yang berarti kondisi kemacetan memakan durasi yang cukup lama.
\end{abstract}

Kata kunci: Simpang, Vissim, traffic light, lalu lintas, kemacetan.

\begin{abstract}
Abstrac. The intersection of the Cisalak I toll gate in Depok City is the intersection that connects the road. Ir. H. Juanda, Jalan Raya Bogor, Jalan Gas Alam, and of course the Cisalak I highway exit \& exit. By having 6 intersection arms, of course there are many traffic conflicts that occur at the Cisalak I toll gate intersection, one of which is a delay in the intersection arm long so that congestion in each intersection during rush hour always occurs and coupled with the cycle time of the traffic light which takes quite a long time so the long queue occurs. The purpose of this study is to know more about the performance of the traffic. The method used is to observe directly to the research location by observing the volume of vehicles with various types, the phase current of the vehicle passing at the intersection, and the cycle time of the traffic light, and by using Vissim software as modeling and getting the results of the count. The results of the study found capacity on the Bogor Highway (Jakarta direction) with a total of 771.69, Jalan Ir. H. Juanda is 542.92, Bogor Highway (Bogor direction) is 612.21, and Cijago / Cisalak \& Natural Gas Toll Road is 538. and the value of degree of saturation in each intersection is Highway Bogor (direction Jakarta) amounting to 2.96, Jalan Ir. H. Juanda is 3.52, Bogor Highway (Bogor direction) is 2.77, and Cijago / Cisalak \& Gas Alam Toll Road is 2.95, so the level of service results in all $F$ crossing arms which means the congestion condition takes up the duration long enough.
\end{abstract}

Keyword: Intersection, Vissim, traffict light, traffict, confgestion.

\section{A. PENDAHULUAN}

Depok merupakan suatu kota yang terletak di provinsi Jawa Barat, Kota Depok merupakan kota yang saling berhubungan antara Jakarta, Bogor, Tanggerang, dan Bekasi atau yang biasa dikenal dengan singkatan "Jabodetabek". Tiap tahunnya perkembangan suatu kota itu sangat pesat sama halnya dengan kota Depok, khususnya untuk perkembangan penduduk yang terus bertambah sangat mempengaruhi tingkat kebutuhan transportasi di kota Depok.

Transportasi merupakan faktor penting dalam kehidupan yang mempunyai peranan menunjang aktivitas manusia sehari-hari. Transportasi ialah suatu proses perpindahan dari tempat asal ke tempat tujuan untuk memenuhi tujuan tertentu, dengan berkembangnya sarana dan prasarana transportasi tentunya sangat memudahkan masyarakat dalam aktivitas sehari-hari.

Dampak dari jumlah penduduk yang tiap tahunnya meningkat maka bertambah juga kebutuhan sarana dan prasarana transportasi. Mobilitas atau pergerakan masyarakat yang tinggi membutuhkan tersedianya sarana dan prasarana yang memadai. Untuk daerah perkotaan pada transportasi darat memiliki masalah yang lebih dominan ketimbang moda transportasi yang lain. Belum terpenuhinya sarana dan prasarana transportasi membuat permasalahan dalam transportasi lalu lintas. Permasalahan lalu lintas perkotaan pada umumnya meliputi kemacetan lalu lintas, angkutan umum, perparikiran, polusi, dan kedisiplinan dalam berlalu lintas.

Simpang gerbang Tol Cisalak I merupakan simpang yang menghubung antara tol Cijago dengan Jl. Raya Bogor dan Jl. Ir. H. Juanda. Simpang gerbang Tol Cisalak I memiliki banyak lengan simpang, dan persimpangan ini memiliki ruas simpang yang rumit. Banyak kendaraan yang keluar dari tol, kendaraan yang membawa container melewati serta lokasi persimpangan yang berdekatan dengan sekolah dasar, universitas, dan pasar Cisalak yang 
menyebabkan ketidaknyamanan pada pengguna jalan. Dari padatnya tersebut menyebabkan antrian kendaraan yang panjang. Oleh karena itu dengan menggunakan perangkat lunak vissim untuk menganalisis simpang tersebut.

\section{B. METODE PENELITIAN}

Penelitian ini dilakukan pendekatan secara analisis kuantitatif, melalui analisis kuantitatif mengolah data dari hasil observasi lalu data tersebut dihitung dan hasil hitungan tersebut di validasi ke lokasi penelitian. Penelitian ini menggunakan pendekatan kuantitatif, yang bertujuan mengetahui kondisi dalam bentuk angka atau real. Prosedur pengambilan data penelitian menggunakan dua jenis data, yang dapat digolongkan sebagai berikut:

\section{Data Primer}

Data primer adalah data yang diperoleh secara langsung melalui pengamatan di simpang bersinyal Cisalak, Kota Depok yang menghasilkan data observasi yang berisi banyaknya kendaraan yang melintas di tiap simpang, waktu siklus traffic light, lebar lajur jalan. Untuk yang banyaknya kendaraan dihitung selama 3 hari, yaitu pada hari Senin, Rabu, dan Sabtu ( tanggal 1,3, dan 6 Juli 2019) dengan 3 koridor waktu yaitu pada pukul 07.00-08.00, 12.00-13.00, dan 17.00-18.00. nanti dari data tersebut dihitung dan dimodelkan dengan perangkat lunak Vissim yang nanti menghasilkan level of service atau tingkat pelayanan seberapa besar kepadatan arus lalu lintas pada simpang bersinyal Cisalak Kota Depok.

2. Data Sekunder

Data sekunder adalah data yang diperoleh tidak melalui pengamatan langsung di lapangan, data sekunder bisa didapat dari buku, atau website di internet. Data sekunder yang diambil untuk penelitian ini ialah kondisi geometric simpang yang didapat dari google maps untuk mengetahui kondisi simpang dan data kependudukan Kota Depok yang nanti dimasukkan dalam perhitungan pada analisis

\section{HASIL DAN PEMBAHASAN}

Berdasarkan hasil penilitan yang dilakukan pada hari senin 1 Juli 2019, rabu 3 Juli 2019, dan sabtu 6 Juli 2019 dapat diketahui volume kendaraan yang lebih pada ketimbang hari yang lain yaitu pada hari senin 1 Juli 2019 pukul 07.00-08.00, dengan volume kendaraan Jalan Raya Bogor (arah Jakarta) sebanyak 6039 kend/jam, volume kendaraan Jalan. Ir. H. Juanda sebanyak 5385 kend/jam, volume kendaraan Jalan Raya Bogor (arah Bogor) sebanyak 4212 kend/jam, dan volume kendaraan Jl. tol Cijago/Cisalak \& Jl. Gas Alam sebanyak 2317 kend/jam. Data volume ini digunakan untuk menganalisa dengan perhitungan MKJI dan permodelan Vissim.

Dari hasil hitungan tersebut didapatkan Tundaan dari MKJI pada masing masing lengan sebesar 3849.37 pada Jalan Raya Bogor arah Jakarta ,4790.72 pada Jalan Ir. H. Juanda ,3444.17 pada Jalan Raya Bogor arah Bogor dan 6203.74 pada jalan exit tol Cijago dan Jalan Gas Alam. Sedangkan dari permodelan Vissim didapat pada masing masing lengan sebesar 107.79 pada Jalan Raya Bogor arah Jakarta, 177.01 pada Jalan Ir. H. Juanda, 167.04 pada Jalan Raya Bogor arah Bogor, dan 178.7 pada jalan exit tol Cijago dan Jalan Gas Alam, dan hasil hitungan pada panjang antrian didapat dari MKJI sebesar 1859,54 pada Jalan Raya Bogor arah Jakarta, 1146,92 pada Jalan Ir. H. Juanda, 1055,51 pada Jalan Raya Bogor arah Bogor, dan 5809,49 pada jalan exit tol Cijago dan Jalan Gas Alam. Sedangkan dari permodelan Vissim didapat sebesar 45,92 m pada Jalan Raya Bogor arah Jakarta, 185,49 m pada Jalan Ir. H. Juanda, 267,34 m pada Jalan Raya Bogor arah Bogor, dan 153,1 m pada jalan exit tol Cijago dan Jalan Gas Alam.

Dari hasil tersebut berbeda mungkin karena faktor perhitungan yang berbeda antara MKJI dengan Vissim, walaupun LOS dari masing masing simpang sama yaitu "F", akan tetapi dari pengamatan penulis, hasil yang lebih sesuai dengan kondisi jalan yaitu dari hasil perhitungan Vissim.

Faktor permasalahan yang ada pada simpang bersinyal Cisalak Kota Depok, ialah :

1. Waktu siklus lampu lalu lintas yang terlalu lama, satu siklus dari lampu merah sampai kembali lagi ke merah memakan waktu selama 351 detik per lengan simpang, yang tentunya ini menyebabkan panjangnya antrian karena waktu tunggu yang terhitung lama.

2. Dari arah jalan exit tol CIjago/Cisalak dengan Jalan Gas Alam bersamaan keluar dari lengan simpang dan akhirnya menjadi hambatan untuk menuju Jalan.Ir.H.Juanda dan Jalan Raya Bogor arah Bogor.

3. Dan tentunya volume kendaraan yang banyak pada saat jam sibuk yang tentunya menyebabkan panjangnya antrian di tiap lengan simpang.

\section{KESIMPULAN}

Berdasarkan hasil pengamatan dan analisis dengan data-data yang ada, dapat disimpulkan sebagai berikut :

1. Faktor yang menyebabkan kemacetan pada simpang gerbang tol cisalak 1 ialah dari siklus waktu yang lama, serta kondisi geometrik yang berupa 6 lengan simpang menyebabkan terjadinya penumpukan di tiap masing masing lengan, lalu juga pada Jalan Gas Alam yang memiliki arus yang memperlambat laju keluar kendaraan dari exit tol Cijago/Cisalak

2. Panjang antrian pada perhitungan Vissim didapat 45,92 m pada Jalan Raya Bogor arah Jakarta, 185,49 m pada 
Jalan Ir. H. Juanda, 267,34 m pada Jalan Raya Bogor arah Bogor, dan 153,1 m pada jalan exit tol Cijago dan Jalan Gas Alam.

3. Tundaan Kendaraan pada perhitungan Vissim sebesar 107.79 pada Jalan Raya Bogor arah Jakarta, 177.01 pada Jalan Ir. H. Juanda, 167.04 pada Jalan Raya Bogor arah Bogor, dan 178.7 pada jalan exit tol Cijago dan Jalan Gas Alam

4. Nilai derajat kejenuhan (DS) di tiap simpang yaitu Jalan Raya Bogor (arah Jakarta) Sebesar 2,96, Jalan Ir. H. Juanda sebesar 3,52, Jalan Raya Bogor (arah Bogor) sebesar 2,77, dan Jalan Tol Cijago/Cisalak \& Gas Alam sebesasr 2,95

5. LOS di tiap simpang sama, yaitu F, yang berarti kepadatan lalu lintas sangat tinggi dan volume rendah serta terjadi kemacetan untuk durasi yang cukup lama.

\section{E. SARAN}

Berdasarkan kesimpulan diatas, penulis mengemukakan saran-saran yang dapat Berdasarkan kesimpulan diatas, penulis mengemukakan saran-saran yang dapat menjadi bahan pertimbangan untuk mengatasi permasalahan pada simpang bersinyal Cisalak, Kota Depok, yaitu:

1. Pemerintah perlu memerhatikan kondisi kepadatan lalu lintas yang tiap tahun selalu meningkat dengan membuat kebijakan-kebijakan baru agar bisa mengurangi banyaknya volume kendaraan

2. Mengurangi waktu siklus lampu lalu lintas, dengan harapan bisa mengurangi tundaan pada simpang.

3. Membuat rute alternatif dalam arti agar penyebaran jalan tidak bertumpuk pada satu titik

4. Arus pada Jalan Gas Alam seharusnya tidak diperbolehkan ke Jalan Ir. H. Juanda karena dia menghambat arus dari exit tol Cijago/Cisalak, seharusnya dari Jalan Gas Alam hanya langsung ke Jalan Raya Bogor (arah Bogor) dan memilih rute lain atau putar arah di suatu titik

\section{F. DAFTAR PUSTAKA}

Departemen Pekerjaan Umum Direktorat Jenderal Bina Marga. (1997). Manual Kapasitas Jalan Indonesia (MKJI)

Dewi, M. R. (2017). Analisis Tingkat Pelayanan Jalan Menggunakan Perhitungan MKJI 1997 dan Perangkat Lunak Vissim Pada Simpang Bersinyal.

Morlok, E. (1991). Pengantar Teknik dan Perencanaan Transportasi. Jakarta: Erlangga. 